\title{
Clinical characteristics and outcome of childhood vesicoureteral reflux
}

\author{
Eda D. Kurt-SukurM.D. ${ }^{a}$, Zeynep B. Özçakar M.D. ${ }^{a}$, Pınar Haznedar-Karakaya M.D. ${ }^{b}$, \\ Songül Yılmaz M.D. ${ }^{a}$, Atilla H. Elhan Ph. D. ${ }^{c}$, Nilgün Çakar M.D. ${ }^{a}$ and \\ Fatoş Yalçınkaya M.D. ${ }^{a}$
}

\begin{abstract}
Introduction. The aim of the study was to assess the clinical features and outcome parameters of children with vesicoureteral reflux (VUR) based on gender and VUR grade.

Population and methods. Patients with VUR who were seen during routine follow-up visits at Ankara University Children's Hospital between January 2014-January 2015 were included in this retrospective study. Patient demographics, clinical course, laboratory investigations, imaging were noted.

Results. Two hundred and twenty patients were recruited. Mean age at the time of diagnosis was 3,17 $\pm 3,08$ years. Boys were diagnosed at younger ages as compared to girls $(2.00 \pm 2,59 \mathrm{vs}$. $3,81 \pm 3.15, \mathrm{p}<0.001$ ). Urinary tractinfection (UTI) was the most common presentation. The second presentation form was antenatal hydronephrosis (AHN) which was more common in males $(25.6 \%, \mathrm{p}<0.001)$. Twenty-two percent of the patients had grade 1-2, $51 \%$ grade 3 and $27 \%$ grade $4-5$ reflux. Patients with grade $4-5$ reflux had more abnormal ultrasound (US) and Tech 99m dimercaptosuccinic acid scintigraphy (DMSA) findings and surgery was performed more frequently in this group $(\mathrm{p}<0.001)$. In males, grade $4-5$ reflux (43.6 \% vs. $18.3 \%)$, abnormal US (77 \% vs. $54 \%$ ) and DMSA (77 \% vs. $59 \%)$ findings were more frequent $(p<0.05)$. In girls higher rates of UTIs, lower urinary tract dysfunction (LUTD) and spontaneous reflux resolution were seen $(\mathrm{p}<0.05)$.

Conclusions: Despite younger age at diagnosis, spontaneous resolution was found lower in boys and they had more frequent $\mathrm{AHN}$, more severe reflux, and radiological abnormalities.

Key words: children, gender identity, vesico-ureteral reflux/grade.
\end{abstract}

http: / / dx.doi.org/10.5546/ aap.2020.eng.e16

To cite: Kurt-Sukur ED, Özçakar ZB, HaznedarKarakaya P, Y1lmaz S, et al. Clinical characteristics and outcome of childhood vesicoureteral refluxe. Arch Argent Pediatr 2020;118(1):e16-e21.
Eda D. Kurt-Şükür, M.D.: didemsukur@gmail.com

Funding:

None.

Conflict of interest:

None.

Received: 2-16-2018

Accepted: 8-14-2019

\section{INTRODUCTION}

Vesicoureteral reflux (VUR) is a congenital defect of the ureterovesical junction which leads to retrograde passage of urine from bladder towards the ureter and kidneys. It is a common condition in childhood however since large-scale population screenings by voiding cystourethrography (VCUG) cannot be performed the precise prevalence of the disease is unknown. It was reported to affect $1 \%$ of healthy children. ${ }^{1}$ Venhola et al., reported a prevalence of $28-36 \%$ in children who underwent VCUG due to presumed urinary tract infection (UTI). ${ }^{2}$ Later the same group published a prevalence of 35-40\%. With a recent study from our center we showed a prevalence of $30.3 \%$ among children who were investigated after first febrile UTI. ${ }^{4}$ Studies on VUR provide heterogenous data regarding the clinical presentation and course of VUR in children. With this retrospective study we aimed to assess possible differences between genders and different grades in VUR patients.

\section{POPULATION AND METHODS}

A retrospective cohort study on children with VUR diagnosis who were seen during routine follow-up visits at Ankara University Children's Hospital between January 2014 and January 2015 was conducted. Inclusion criteria were being under the age of 16 years at diagnosis, having radiologically confirmed VUR by VCUG and minimum followup time of 6 months. Patients with chronic kidney disease and renal transplantation were excluded. Two hundred and twenty patients were 
found eligible. Data of the patients were gathered from the hospital files. Patient demographics (age, gender, antenatal findings), clinical course (follow-up period, number of UTIs, lower urinary tract dysfunction, spontaneous resolution / surgery), laboratory investigations (urine culture), imaging (ultrasound, scintigraphy, VCUG) were noted. Antenatal hydronephrosis (AHN) was diagnosed by ultrasonography (US) when anteroposterior diameter of renal pelvis was $\geq 4 \mathrm{~mm}$ in the second and $\geq 7 \mathrm{~mm}$ in the third trimester of pregnancy. ${ }^{5}$ Hydronephrosis was further classified according to the Society for Fetal Urology grading system as grade 1, mild dilatation of the renal pelvis; grade 2, dilatation of the pelvis with dilatation of few calyces; grade 3 , nearly all calyces dilated and grade 4 , with paranchymal thinning. ${ }^{6}$ Changing degree of hydronephrosis / hydroureteronephrosis, decrease in renal size on serial prenatal US examinations were taken into account during follow-up of the patients. Thickened renal pelvis and/or ureter walls, dilated ureters were also considered as features of VUR on US. Diagnosis of VUR was made by demonstration of reflux of urine into the upper urinary tract by conventional VCUG. Grading of VUR was done according to the International Reflux Study Group classification; mild (grade 1-2), moderate (3), severe (4-5). ${ }^{7}$ Urine cultures were obtained during routine examination or whenever the patient had fever or urinary symptoms. Urinary tract infection was diagnosed when there were $\geq 100.000$ colony forming unit (CFU) of a single pathogen $/ \mathrm{ml}$ of urine specimen obtained by clean catch method and $\geq 10.000 \mathrm{CFU} / \mathrm{ml}$ by bladder catheterization in children with fever $\left(\geq 38^{\circ} \mathrm{C}\right)$ and / or symptoms. Renal scarring on Tech $99 \mathrm{~m}$ dimercaptosuccinic acid scintigraphy (DMSA) was defined as decreased uptake with loss of contours or cortical thinning with distortion of parenchymal volume. Lower urinary tract dysfunction (LUTD) was questioned in children older than 4 years of age and defined based on clinical history (day-time incontinence, urgency, frequency etc.). Reflux resolution was shown by performing control VCUG after minimum 1 year of follow-up. Surgery was performed when patients had recurrent UTIs under antibiotic prophylaxis. Patients were divided into groups according to gender and reflux grade. Ethical approval was obtained from the Institutional Ethics Board of Ankara University School of Medicine.
Results are given as a mean \pm standard deviation or proportion as appropriate. Categorical variables were evaluated by Chi-square test or Fisher's Exact Test where applicable. Comparison between two groups for the non-normally distributed continuous variables was assessed by Mann Whitney U test. Difference among three groups for the nonnormally distributed continuous variables was evaluated by Kruskal-Wallis variance analysis. A $p$ value $<0.05$ was considered statistically significant.

\section{RESULTS}

Two hundred and twenty VUR patients were recruited. Mean age at the time of the study was $9.07 \pm 4.52$ years and female-to-male ratio was 1,82 . Ultrasound imaging was performed

TABLE 1. Baseline demographic and clinical characteristics of 220 patients

\begin{tabular}{|c|c|}
\hline Parameter & Mean \pm SD/n $(\%)$ \\
\hline \multicolumn{2}{|l|}{ Age } \\
\hline Age at VUR diagnosis (years) & $3.17 \pm 3.08$ \\
\hline Follow-up period (years) & $5.07 \pm 3.31$ \\
\hline \multicolumn{2}{|l|}{ Gender } \\
\hline Girls & $142(64.5)$ \\
\hline Boys & $78(35.5)$ \\
\hline \multicolumn{2}{|l|}{ Cause for VUR diagnosis } \\
\hline UTI & $161(73.2)$ \\
\hline $\mathrm{AHN}$ & $25(11.4)$ \\
\hline Voiding dysfunction & $20(9)$ \\
\hline Others & $14(6.4)$ \\
\hline \multicolumn{2}{|l|}{ US- first } \\
\hline Normal & $84(38)$ \\
\hline Pelvicalyceal dilatation & $82(37.3)$ \\
\hline Renal atrophy/ hypoplasia & $21(9.5)$ \\
\hline Bladder irregularity & $11(5)$ \\
\hline Others & $22(10)$ \\
\hline \multicolumn{2}{|l|}{ DMSA- 202 patients } \\
\hline Normal & $70(34.7)$ \\
\hline Heterogenous activity & $74(36.6)$ \\
\hline Border irregularity & $35(17.3)$ \\
\hline Decreased kidney size & $23(11.4)$ \\
\hline \multicolumn{2}{|l|}{ VUR Grade } \\
\hline I-II & $48(21.8)$ \\
\hline III & $112(50.9)$ \\
\hline IV-V & $60(27.3)$ \\
\hline \multicolumn{2}{|l|}{ VUR outcome } \\
\hline Spontaneous resolution & $57(26)$ \\
\hline Resolution with surgery & $96(43.6)$ \\
\hline Not resolved & $67(30.4)$ \\
\hline UTI (at least one during follow-up) & $200(90.9)$ \\
\hline
\end{tabular}

AHN: antenatal hydronephrosis,

DMSA: dimercaptosuccinic acid scintigraphy, US: ultrasound, UTI: urinary tract infection, VUR: vesicoureteral reflux 
to all patients and Tc-99mDMSA scintigraphy to 202 patients. There were 171 patients (77 \%) who were followed up for 3 and more years and 21 patients seen for less than 2 years. One hundred and four patients $(47.2 \%)$ underwent surgery; among them 66 patients had subureteric injection, 31 ureteroneocystostomy, 6 patients had nephrectomy and one patient posterior urethral valve resection. At least one control VCUG was performed in all patients. Sixty-two patients $(28 \%)$ had accompanying congenital urinary system anomalies. Table 1 depicts main demographics of the study population.

Comparison of patients according to gender is given in Table 2. Mean follow up time was similar for both sexes ( $\sim 5$ years). Forty-two male patients $(53.8 \%)$ were diagnosed under one year of age and oldest male patient diagnosed was 10 years old at the time of diagnosis. Among girls, $108(76 \%)$ were diagnosed at the ages of
1 and older. In boys AHN was significantly more common and reflux grade was found to be higher among them. Number of acute pyelonephritis (APN) and lower UTI episodes during followup were found significantly higher in girls as compared to boys $2.86 \pm 2.5$ vs. $1.69 \pm 1.91$ for APN and $2.21 \pm 3.19$ vs. $0.97 \pm 2.22$ for lower UTI $(\mathrm{p}<0.001)$ respectively. Extended spectrum beta lactamase (ESBL) producing uropathogens were more commonly isolated in girls than boys; $26.2 \%$ vs. $14.1 \%(\mathrm{p}=0.038)$.

When grouped according to the grade of reflux it was noted that the younger the age of the patient the more severe the reflux was observed. Males had higher grades of reflux. Antenatal hydronephrosis as a clue for diagnosis was seen significantly more common in severe reflux compared to other grades. Similarly, abnormal radiological findings were more frequent among severe reflux patients and they underwent

TABLE 2. Characteristics of patients according to gender

\begin{tabular}{|c|c|c|c|}
\hline & $\begin{array}{c}\text { Female } \\
\mathrm{n}=142(\%)\end{array}$ & $\begin{array}{c}\text { Male } \\
\mathbf{n}=78(\%)\end{array}$ & $P$ value \\
\hline Age at diagnosis (mean \pm SD) & $3.8 \pm 3.15$ & $2.00 \pm 2.59$ & $<0.001$ \\
\hline Cause for VUR diagnosis, $\mathbf{n}(\%)$ & & & $<0.001$ \\
\hline UTI & $115(81)$ & $46(59)$ & \\
\hline AHN & $5(3.5)$ & $20(25.6)$ & \\
\hline Voiding dysfunction & $16(11.3)$ & $4(5.1)$ & \\
\hline Others & $6(4.2)$ & $8(10.3)$ & \\
\hline VUR grade, $\mathrm{n}(\%)$ & & & $<0.001$ \\
\hline I-II & $37(26.1)$ & $11(14.1)$ & \\
\hline III & $79(55.6)$ & $33(42.3)$ & \\
\hline IV-V & $26(18.3)$ & $34(43.6)$ & \\
\hline USG, n (\%) & & & 0.001 \\
\hline Normal & $66(46.5)$ & $18(23.1)$ & \\
\hline Abnormal & $76(53.5)$ & $60(76.9)$ & \\
\hline DMSA, $\mathrm{n}=202(\%)$ & & & 0.014 \\
\hline Normal & $54(40.6)$ & $16(23.2)$ & \\
\hline Abnormal & $79(59.4)$ & $53(76.8)$ & \\
\hline Voiding dysfunction, n: $135(\%)$ & & & 0.002 \\
\hline Present & $77(72.6)$ & $12(41.4)$ & \\
\hline Not present & $29(27.4)$ & $17(58.6)$ & \\
\hline VUR outcome, n (\%) & & & 0.012 \\
\hline Resolved & $107(75.4)$ & $46(59)$ & \\
\hline Not resolved & $35(24.6)$ & $32(41)$ & \\
\hline VUR outcome, n (\%) & & & 0.012 \\
\hline Spontaneous resolution & $44(31.1)$ & $13(16.7)$ & \\
\hline Resolution with surgery & $63(44.3)$ & $33(42.3)$ & \\
\hline Not resolved & $35(24.6)$ & $32(41)$ & \\
\hline
\end{tabular}

AHN: antenatal hydronephrosis, DMSA: dimercaptosuccinic acid scintigraphy, US: ultrasound, UTI: urinary tract infection, VUR: vesicoureteral reflux. 
surgery more often. There was no statistically significant difference between different grades of reflux when number of APN or lower UTI episodes during follow-up were considered $(p>0.05)$. Table 3 summarizes the features of the patients according to the grade of reflux.

\section{DISCUSSION}

In this retrospective study, clinical findings and course of patients with VUR $(80 \%$ with high grade reflux) were investigated. Male and female patients differed significantly regarding to their presentation, grade of reflux, radiological findings and course. Grade of reflux was also a major determinant concerning presentation and outcome of these patients.

Urinary tract infection was the leading cause of diagnosis (73\%) in our study consistent with the literature. Antenatal hydronephrosis was the second and LUTD the third cause. It has been known that girls with VUR generally present with UTIs and infant boys are generally diagnosed during investigations for congenital urinary abnormalities. ${ }^{8}$ Similarly, in our study boys were diagnosed at younger ages and AHN was more common among them. Moreover, boys had greater degrees of reflux and more frequent abnormal radiological findings. When outcome was considered in males the percentage of patients who did not show resolution was significantly higher as compared to girls; $41 \%$ vs. $25 \%$ respectively $(\mathrm{p}<0.05)$. Silva et al. showed that infant boys presented with more severe reflux, had greater prevalence of renal damage, however they found that clinical outcomes in both gender groups were similar. ${ }^{9}$ Nakai et al., reported more frequent renal parenchymal lesions in infant boys with primary VUR. ${ }^{10}$ The relatively young age of this infant group and prenatal diagnosis of sterile reflux together strengthen the idea that VUR is a developmental disease of the urogenital system and not all renal damage may result from recurrent UTIs. We know that there is a strong relationship between VUR and LUTD. It has been speculated that VUR may be secondary to LUTD in some patients. ${ }^{11}$ The Swedish reflux trial showed that in patients with grades 3 and 4 reflux, recurrent UTIs were seen in $33 \%$ of children with LUTD and in $20 \%$ of those without LUTD. ${ }^{12}$ In our study among girls UTIs and LUTD were significantly more common.

Moderate to severe grades of reflux constituted the majority of our patients; $27.3 \%$ of them had grades 4-5 of VUR. Similarly, Hanula et al reported around $20 \%$ of high-grade reflux among 2036 children. ${ }^{3}$ In our study the grade $4-5$ group was mainly composed of males, they had more frequent US and DMSA abnormalities and

TABLE 3. Comparison of clinical characteristics according to reflux grade

\begin{tabular}{|c|c|c|c|c|}
\hline & $\begin{array}{l}\text { Grade I-II } \\
\mathrm{n}=48(\%)\end{array}$ & $\begin{array}{l}\text { Grade III } \\
\mathrm{n}=112(\%)\end{array}$ & $\begin{array}{c}\text { Grade IV-V } \\
\mathrm{n}=60(\%)\end{array}$ & $P$ value \\
\hline Age at diagnosis -years- (mean \pm SD) & $3.42 \pm 3.16$ & $3.43 \pm 3.06$ & $2.48 \pm 3.02$ & 0.010 \\
\hline Follow-up period -years- (mean $\pm S \mathrm{D}$ ) & $4.72 \pm 3.10$ & $5.12 \pm 3.26$ & $5.26 \pm 3.59$ & 0.796 \\
\hline $\begin{array}{l}\text { Gender } \\
\text { Female } \\
\text { Male }\end{array}$ & $\begin{array}{l}37(77.1) \\
11(22.9)\end{array}$ & $\begin{array}{l}79(70.5) \\
33(29.5)\end{array}$ & $\begin{array}{l}26(43.3) \\
34(56.7)\end{array}$ & $<0.001$ \\
\hline $\begin{array}{l}\text { Cause for VUR diagnosis } \\
\text { UTI } \\
\text { AHN } \\
\text { Voiding dysfunction } \\
\text { Others }\end{array}$ & $\begin{array}{l}41(85.4) \\
1(2.1) \\
2(4.2) \\
4(8.3)\end{array}$ & $\begin{aligned} 85 & (75.9) \\
8 & (7.1) \\
13 & (11.6) \\
6 & (5.4)\end{aligned}$ & $\begin{array}{c}35(58.3) \\
16(26.7) \\
5(8.3) \\
4(6.7)\end{array}$ & 0.001 \\
\hline $\begin{array}{l}\text { US } \\
\text { Normal } \\
\text { Abnormal }\end{array}$ & $\begin{array}{l}24(50) \\
24(50)\end{array}$ & $\begin{array}{l}52(46.4) \\
60(53.6)\end{array}$ & $\begin{array}{c}8(13.3) \\
52(86.7)\end{array}$ & $<0.001$ \\
\hline $\begin{array}{l}\text { DMSA, } \mathbf{n}=\mathbf{2 0 2} \\
\text { Normal } \\
\text { Abnormal }\end{array}$ & $\begin{array}{l}20(46.5) \\
23(53.5)\end{array}$ & $\begin{array}{l}43(41.7) \\
60(58.3)\end{array}$ & $\begin{array}{c}7(12.5) \\
49(87.5)\end{array}$ & $<0.001$ \\
\hline $\begin{array}{l}\text { VUR outcome } \\
\text { Spontaneous resolution } \\
\text { Resolution with surgery } \\
\text { Not resolved }\end{array}$ & $\begin{array}{l}18(37.5) \\
7(14.5) \\
23(48)\end{array}$ & $\begin{array}{l}35(31.3) \\
50(44.6) \\
27(24.1)\end{array}$ & $\begin{array}{c}4(6.7) \\
39(65) \\
17(28.3)\end{array}$ & $<0.001$ \\
\hline
\end{tabular}

AHN: antenatal hydronephrosis, DMSA: dimercaptosuccinic acid scintigraphy, US: ultrasound, UTI: urinary tract infection, VUR: vesicoureteral reflux. 
surgery was performed more frequently among them. They got their diagnosis mainly after UTIs but AHN was found in nearly $1 / 3$ of this highgrade reflux group which constituted less than $10 \%$ of grades 1-3 which were in accordance with the literature..$^{9,10}$

Despite the fact that most prospective studies about VUR are small, the analyses show that the prognosis is generally good. Smellie et al reported that after 10 years of follow-up reflux resolution was seen in $52 \%$ of the patients. ${ }^{13}$ In our study, $26 \%$ of the patients showed spontaneous resolution and this may be attributed to our relatively short follow-up period. Our mean follow-up time was approximately 5 years and more than $3 / 4$ of the patients were followed up for 3 and more years. Cannon et al. reported male gender, age at diagnosis less than one-year-old, low grade VUR at presentation as predictors of spontaneous resolution. ${ }^{14}$ However, in our study, we showed that in boys spontaneous resolution was significantly lower and they were younger and had more severe reflux compared to girls.

Ultrasound and DMSA scintigraphy were the imaging modalities most commonly used for the evaluation of patients with VUR. In our study US was performed in every patient and was found normal in $38 \%$ of patients with any grade of VUR. Dimercaptosuccinic acid scintigraphy scans were normal in $35.3 \%$ of patients. As expected in higher grades of reflux US abnormalities were more frequent. Strikingly when grouped according to gender pathological US findings were more common in boys as compared to girls (77 \% vs $54 \%$, p $<0.001)$. Similar findings were observed for DMSA results. Abnormal DMSA findings were significantly higher in males $(p=0.014)$ and in severe reflux $(p<0.001)$. Considering the higher degrees of reflux among boys and their young age in our study, the hypothesis that renal parenchymal damage may be a result of congenital maldevelopment rather than of VUR can be the reason for this finding. ${ }^{15}$

Voiding cystourethrography is the gold standard for VUR diagnosis. To eliminate the need for catheterization and/or radiation exposure modalities like DMSA and USG are also being used. There has always been a debate on the order of radiological techniques to be used for VUR evaluation. The urological approach suggests the use of VCUG for all children less than 2 years after the first confirmed APN. ${ }^{16}$ From the nephrology point of view a recent study showed the use of DMSA as a first step had significant value. ${ }^{17}$ Shaikh et al reported in their systematic review that neither US nor DMSA was accurate enough to detect VUR in children. ${ }^{18}$ In general US is considered as a poor screening test for genitourinary abnormalities and it rather is viewed as a complementary method together with VCUG and DMSA. Sensitivity of US for any abnormal findings on VCUG was shown to range from $5 \%$ (specificity: $97 \%$ ) to $28 \%$ (specificity: $77 \%$ ). ${ }^{19}$ A meta-analysis showed sensitivity of DMSA scintigraphy as $60,8 \%$ and specificity as $53,7 \%$ from 13 different studies. ${ }^{20}$ In our study patients who were diagnosed as VUR by VCUG were included and sensitivity of US and DMSA were found to be $6 \%$ and $65 \%$ respectively.

The small sample size, the retrospective manner of the study and relatively short followup were the major limitations of our study.

\section{CONCLUSIONS}

In patients with severe reflux, AHN and male gender were found to be significantly more frequent with more abnormal radiological findings which we believe showed the footprints of VUR starting from the in-utero period. Boys had higher grades of VUR, lower spontaneous resolution rate and AHN was more commonly seen among them. With antenatal screening and careful pediatric assessment of especially male infants VUR patients may be diagnosed and intervened early.

\section{REFERENCES}

1. Diamond DA, Mattoo TK. Endoscopic treatment of primary vesicoureteral reflux. N Engl J Med. 2012; 366(13):1218-26.

2. Venhola M, Hanula A, Huttunen NP, Renko M, et al. Occurrence of vesicoureteral reflux in children. Acta Paediatr 2010; 99(12):1875-8.

3. Hannula A, Venhola M, Renko M, Pokka T, et al. Vesicoureteral reflux in children with suspected and proven urinary tract infection. Pediatr Nephrol. 2010; 25(8):1463-9.

4. Yilmaz S, Özçakar ZB, Kurt-Sükür ED, Bulum B, et al. Vesicoureteral reflux and renal scarring risk in children after the first febrile urinary tract infection. Nephron. 2016; 132(3):175-80.

5. Nguyen HT, Herndon CD, Cooper C, Gatti J, et al. The Society for Fetal Urology consensus statement on the evaluation and management of antenatal hydronephrosis. J Pediatr Urol. 2010; 6(3):212-31.

6. Fernbach SK, Maizels M, Conway JJ. Ultrasound grading of hydronephrosis: introduction to the system used by the Society for Fetal Urology. Pediatr Radiol. 1993; 23(6):478-80.

7. Medical versus surgical treatment of primary vesicoureteral reflux: report of the International Reflux Study Committee. Pediatrics. 1981; 67(3):392-400.

8. Marchini GS, Onal B, Guo CY, Rowe CK, et al. Genome gender diversity in affected sib-pairs with familial vesicoureteric reflux identified by single nucleotide polymorphism linkage analysis. BJU Int. 2012; 109(11):1709-14. 
9. Silva JM, Oliveira EA, Diniz JS, Cardoso LS, et al. Gender and vesico-ureteral reflux: a multivariate analysis. Pediatr Nephrol. 2006; 21(4):510-6.

10. Nakai H, Kakizaki H, Konda R, Hayashi $Y$, et al. Clinical characteristics of primary vesico-ureteral reflux in infants: multicenter retrospective study in Japan. J Urol. 2003; 169(1):309-12.

11. Lee H, Lee YS, Im YJ, Han SW. Vesicoureteral reflux and bladder dysfunction. Transl Androl Urol. 2012; 1(3):153-9.

12. Sillén U, Brandström $P$, Jodal U, Holmdahl G, et al. The Swedish reflux trial in children: v. Bladder dysfunction. J Urol. 2010; 184(1):298-304.

13. Smellie JM, Jodal U, Lax H, Möbius TT, et al. Outcome at 10 years of severe vesicoureteral reflux managed medically: Report of the International Reflux Study in Children. $J$ Pediatr. 2001; 139(5):656-63.

14. Cannon GM Jr, Arahna AA, Graham DA, Passerotti CC, et al. Improvement in vesicoureteral reflux grade on serial imaging predicts resolution. J Urol. 2010; 183(2):709-13.
15. Williams G, Fletcher JT, Alexander SI, Craig JC. Vesicoureteral reflux. J Am Soc Nephrol. 2008; 19(5):847-62.

16. Tekgül S, Riedmiller H, Hoebeke P, Kočvara R, et al. EAU guidelines on vesioureteral reflux in children. Eur Urol. 2012; 62(3):534-42.

17. Jang KM, Lim MH, Park YH, Kim S. Clinical efficacy of a top-down approach for children with a first febrile urinary tract infection. Child Kidney Dis. 2017; 21(2):114-20.

18. Shaikh N, Spingarn RB, Hum SW. Dimercaptosuccinic acid scan or ultrasound in screening for vesicoureteral reflux among children with urinary tract infections. Cochrane Database Syst Rev. 2016; 7:CD010657.

19. Nelson CP, JohnsonEK, LogvinenkoT, Chow JS. Ultrasound as a screening test for genitourinary anomalies in children with UTI. Pediatrics. 2014; 133(3):e394-403.

20. Mantadakis E, Vouloumanou EK, Georgantzi GG, Tsalkidis A, et al. Acute Tc $99 \mathrm{~m}$ DMSA scan for identifying dilating vesicoureteral reflux in children: a meta-analysis. Pediatrics. 2011; 128(1):169-79. 